\title{
The Solution of Nonlinear Parabolic Equation Using Variational Iteration Method
}

\section{Penyelesaian Persamaan Parabolik Nonlinier Menggunakan Metode Iterasi Variasi}

\author{
Wartono $^{1^{*}}$, Mohammad Hanafi ${ }^{2}$, Irma Suryani ${ }^{3}$
}

\begin{abstract}
Variational iteration method is a semi analytic solution used to solve the parabolic differential equation both of homogen or nonhomogen. In the process of determining an approximation solution, this method did not use a linearization and a small pertubation. In this paper, the variational iteration method is implemented in the parabolic differential equation in the form of $u_{\mathrm{t}}=u_{x x}+\phi(u)+g(x, t)$ with appropriate intial condition. Furthermore, some examples of special parabolic differential equations are given to test the reliability and convergence of the method. Based on the result of study shows that the variational iteration method is able to solve the parabolic differential equation with a good accuration.
\end{abstract}

Keywords: Variational iteration method, nonlinear parabolic differential equation, semi analytical method.

\begin{abstract}
Abstrak
Metode iterasi variasional merupakan metode semi analitik yang digunakan untuk menyelesaikan persamaan diferensial parsial nonlinier baik homogen maupun nonhomogen. Pada proses menentukan solusi hampiran, metode ini tidak memerlukan linierisasi dan pertubasi. Pada artikel ini, metode iterasi variasional diimplementasikan pada persamaan diferensial parsial parabolik dalam bentuk $u_{\mathrm{t}}=u_{x x}+\phi(u)+g(x, t)$ berdasarkan syarat awal. Selanjutnya, beberapa contoh persamaan diferensial parabolik khusus diberikan untuk menguji reabilitas dan konvergensi metode ini. Berdasarkan hasil kajian diperoleh bahwa metode iterasi variasional dapat menyelesaikan persamaan diferensial parabolik dengan akurasi yang baik.
\end{abstract}

Kata kunci: Metode iterasi variasi, persamaan diferensial parabolik nonlinier, metode semi analitik.

\section{Pendahuluan}

Persamaan diferensial parabolik merupakan representasi matematis yang mendeskripsikan fenomena-fenomena sains dan teknik yang bergantung pada variabel waktu. Fenomena-fenomena tersebut diantaranya: konduksi panas, persoalan ekologi dan biologi, dinamika gas dan fluida, hidrodinamik, akustik, reaksi kimia, populasi genetik dan difusi partikel [1].

Persamaan diferensial parabolik yang dihasilkan dari fenomena-fenomena tersebut memiliki bentuk nonlinier dan kompleks sehingga penyelesaian eksaknya sangat sulit untuk ditentukan. Oleh karena itu, beberapa teknik penyelesaian semi analitik telah sukses

\footnotetext{
${ }^{1,2,3}$ Program Studi Matematika, Universitas Islam Negeri Sultan Syarif Kasim Riau
}

*e-mail : ${ }^{1}$ wartono@uin-suska.ac.id, ${ }^{3}$ irmayath@yahoo.co.id 
digunakan untuk menentukan penyelesaian berbagai tipe persamaan diferensial parabolik nonlinear, seperti metode dekomposisi Adomian [2, 3, 4, 5], metode dekomposisi Adomian Laplace [6], metode analisis homotopi [7, 8, 9], metode transformasi diferensial [10, 11], metode pertubasi homotopi $[12,13]$. Selain metode metode-metode yang disebutkan di atas, terdapat teknik lain yang dapat digunakan untuk menyelesaikan persamaan diferensial parabolik nolinier, yaitu metode iterasi variasi.

Metode iterasi variasi dikemukakan dan dikembangkan oleh He [14]. Metode ini dikontruksi sebagai sebuah fungsi koreksi yang memuat pengali Lagrange. Tidak seperti metode semi analitik lainnnya, kontruksi metode iterasi variasi tidak melibatkan linierisasi atau gangguan kecil. Metode ini juga telah sukses menyelesaikan berbagai tipe persamaan diferensial, baik elementer maupun parsial, seperti: persamaan Duffing dan pendulum [15], persaman Lotka-Volterra satu spesies [16], persamaan parabolik linear [17], sistem persamaan diferensial integral [18], problem Lane-Emden dan Emden-Fowler [19], dan sistem persamaan integral diferensial fuzzy Volterra linier [20].

Makalah ini membahas implementasi metode iterasi variasi pada persamaan diferensial parabolik yang dikemukakan oleh Ghotbi dkk [17] dengan menambahkan bentuk nonlinear. Selanjutnya untuk mengetahui kekonvergenan dari penyelesaian hampiran yang dihasilkan, pada beberapa iterasi dihitung galat mutlaknya.

\section{Metode Iterasi Variasi}

Untuk menggambarkan teknik konsep dasar, selanjutnya pertimbangkan bentuk umum persamaan diferensial berikut [15]:

$$
L u+N u=g(x, t) .
$$

Misalkan $L u=L_{t} u+L_{x} u$ maka Persamaan (1) dapat ditulis kembali menjadi

$$
L_{t} u+L_{x} u+N u-g(x, t)=0,
$$

dengan $L_{x}$ dan $L_{t}$ adalah masing-masing operator linier terhadap $x$ dan $t, N$ adalah operator nonlinier dan $g(x, t)$ adalah fungsi kontinu. Berdasarkan metode iterasi variasi, dikontruksi suatu fungsi koreksi untuk Persamaan (2) dalam bentuk

$$
u_{n+1}(x, t)=u_{n}(x, t)+\int_{0}^{t} \lambda(\tau)\left(L_{\tau} u_{n}(x, \tau)+L_{x} \tilde{u}_{n}(x, \tau)+N \tilde{u}_{n}(x, \tau)-g(x, t)\right) \partial \tau,
$$

dengan $\lambda(\tau)$ adalah fungsi pengali Langrange dan dapat diidentifikasi secara optimal menggunakan teori kalkulus variasi, $\tilde{u}_{n}$ adalah variasi terbatas sehingga menjadikan $\delta \tilde{u}_{n}=0$ untuk mencapai kondisi stasioner, dan $u_{0}$ dipilih berdasarkan syarat awal yang diberikan.

Misalkan $u_{n}$ adalah penyelesaian hampiran pada iterasi ke- $n(n \geq 0)$, maka penyelesaian eksak dari (2) diberikan oleh

$$
u(x, t)=\lim _{n \rightarrow \infty} u_{n}(x, t),
$$

sedangkan galat pada iterasi ke- $n$ dihitung dengan menggunakan rumus

$$
E_{n}=\left|u(x, t)-u_{n}(x, t)\right|[21] .
$$

\section{Implementasi Metode Iterasi Variasi pada Persamaan Parabolik}

Untuk mengkontruksi bentuk fungsi koreksi, pertimbangan kembali persamaan diferensial parsial parabolik berikut

$$
\frac{\partial u}{\partial t}-\frac{\partial^{2} u}{\partial x^{2}}=\phi(u)+g(x, t),
$$

dengan syarat batas $u(0, t)=u(1, t)=0$ dan syarat awal $u(x, 0)=f(x)$.

Misalkan $L_{t}=\frac{\partial}{\partial t}$ dan $L_{x x}=\frac{\partial^{2}}{\partial x^{2}}$ adalah operator linier diferensial, maka Persamaan (6) dapat ditulis dalam bentuk 


\section{Wartono, Mohammad Hanafi, Irma Suryani}

$$
L_{t} u-L_{x x} u=\phi(u)+g(x, t),
$$

atau

$$
L_{t} u-L_{x x} u-\phi(u)-g(x, t)=0 .
$$

Komponen $\phi(u)$ pada persaman (7) merupakan fungsi berbentuk nonlinier. Persamaan (7) dikatakan homogen apabila $g(x, t)=0$. Namun sebaliknya, jika $g(x, t) \neq 0$, maka Persamaan (7) dikatakan nonhomogen.

Untuk menyelesaikan Persamaan (7), maka berdasarkan metode iterasi variasi Persamaan (7) dapat diubah menjadi

$$
u_{n+1}(x, t)=u_{n}(x, t)+\int_{0}^{t} \lambda(\tau)\left(L_{\tau} u_{n}(x, \tau)-L_{x x} \tilde{u}_{n}(x, \tau)-\phi\left(\tilde{u}_{n}(x, \tau)\right)-g(x, t)\right) d \tau
$$

dengan $\lambda(\tau)$ adalah pengali Lagrange. Nilai pengali Lagrange $\lambda(\tau)$ dapat diidentifikasi secara optimal melalui teori variasi. Oleh karena itu, persamaan (8) dapat dibentuk menjadi

$$
\delta u_{n+1}(x, t)=\delta u_{n}(x, t)+\delta \int_{0}^{t} \lambda(\tau)\left(L_{\tau} u_{n}(x, \tau)-L_{x x} \tilde{u}_{n}(x, \tau)-\phi\left(\tilde{u}_{n}(x, \tau)\right)-g(x, t)\right) d \tau .
$$

Untuk mencapai kondisi stasioner diperlukan syarat $\delta \tilde{u}_{n}=0$, sehingga Persamaan (9) menjadi

$$
\delta u_{n+1}(x, t)=\delta u_{n}(x, t)+\delta \int_{0}^{t} \lambda(\tau) \frac{\partial u_{n}(x, \tau)}{\partial \tau} d \tau
$$

atau

$$
\delta u_{n+1}(x, t)=\delta u_{n}(x, t)\left(1+\left.\lambda\right|_{\tau=t}\right)-\int_{0}^{t} \lambda^{\prime}(\tau) \delta \frac{\partial u_{n}(x, \tau)}{\partial \tau} d \tau .
$$

Pada saat kondisi stasioner maka dari Persamaan (10), kita mempunyai $\left.\lambda^{\prime}(\tau)\right|_{\tau=\mathrm{t}}=0$ dan $1+\left.\lambda(\tau)\right|_{\tau=\mathrm{t}}=0$ sehingga diperoleh $\lambda=-1$. Kemudian dengan mengganti nilai pengali Lagrange pada Persamaan (8), maka Persamaan (8) dapat ditulis kembali menjadi

$$
u_{n+1}(x, t)=u_{n}(x, t)-\int_{0}^{t}\left(L_{\tau} u_{n}(x, \tau)-L_{x x} u_{n}(x, \tau)-\phi\left(u_{n}(x, \tau)\right)-g(x, \tau)\right) d \tau .
$$

atau

$$
u_{n+1}(x, t)=u_{n}(x, t)+\int_{0}^{t}\left(\frac{\partial u_{n}(x, \tau)}{\partial \tau}-\frac{\partial^{2} u_{n}(x, \tau)}{\partial x^{2}}-\phi\left(u_{n}(x, \tau)\right)-g(x, \tau)\right) d \tau
$$

Berdasarkan Pesamaan (12), selanjutnya dengan mengambil nilai awal $u_{0}(x, t)$, maka diperoleh berturut $u_{1}(x, t) u_{2}(x, t), u_{3}(x, t) \ldots$ dalam bentuk

$$
\begin{aligned}
& u_{1}(x, t)=u_{0}(x, t)-\int_{0}^{t}\left(\frac{\partial u_{0}(x, \tau)}{\partial \tau}-\frac{\partial^{2} u_{0}(x, \tau)}{\partial x^{2}}-\phi\left(u_{0}(x, \tau)\right)-g(x, \tau)\right) d \tau \\
& u_{2}(x, t)=u_{1}(x, t)-\int_{0}^{t}\left(\frac{\partial u_{1}(x, \tau)}{\partial \tau}-\frac{\partial^{2} u_{1}(x, \tau)}{\partial x^{2}}-\phi\left(u_{1}(x, \tau)\right)-g(x, \tau)\right) d \tau \\
& u_{3}(x, t)=u_{2}(x, t)-\int_{0}^{t}\left(\frac{\partial u_{2}(x, \tau)}{\partial \tau}-\frac{\partial^{2} u_{2}(x, \tau)}{\partial x^{2}}-\phi\left(u_{2}(x, \tau)\right)-g(x, \tau)\right) d \tau
\end{aligned}
$$

\section{Aplikasi Numerik}

Pada bagian ini, metode iterasi variasi pada Persamaan (12) di implementasikan terhadap beberapa persoalan persamaan diferensial parabolik nonlinear. Hasil numerik akan dibandingkan dengan penyelesaian eksaknya dan galat yang dihasilkan diplot untuk beberapa iterasi. 


\section{Wartono, Mohammad Hanafi, Irma Suryani}

\section{Contoh 1.}

Pertimbangkan persamaan differensial parsial parabolik nonlinear berikut ini,

$$
\frac{\partial u}{\partial t}-\frac{\partial^{2} u}{\partial x^{2}}=u^{2}-\left(\frac{\partial u}{\partial x}\right)^{2}
$$

dengan syarat awal $u(x, 0)=e^{x}[3]$.

Penyelesaian persamaan parabolik nonlinier pada persamaan (13) menggunakan metode iterasi variasi dilakukan dengan menentukan nilai $u_{1}(x, t), u_{2}(x, t), u_{3}(x, t), \ldots, u_{n}(x, t)$. Oleh karena itu, dengan menggunakan Persamaan (12), maka bentuk iterasi dari Persamaan (13) diberikan oleh

$$
u_{n+1}(x, t)=u_{n}(x, t)-\int_{0}^{t}\left(\frac{\partial u_{n}(x, \tau)}{\partial \tau}-\frac{\partial^{2} u_{n}(x, \tau)}{\partial x^{2}}-u_{n}^{2}(x, \tau)+\left(\frac{\partial u_{n}(x, \tau)}{\partial x}\right)^{2}\right) d \tau
$$

Berdasarkan syarat awal $u_{0}(x, 0)=\exp (x)$, maka dari Persamaan (14) diperoleh berturut-turut

$$
\begin{aligned}
& u_{1}(x, t)=e^{x}(1+t), \\
& u_{2}(x, t)=e^{x}\left(1+t+\frac{t^{2}}{2 !}\right), \\
& u_{3}(x, t)=e^{x}\left(1+t+\frac{t^{2}}{2 !}+\frac{t^{3}}{3 !}\right), \\
& \vdots \\
& u_{n}(x, t)=e^{x}\left(1+t+\frac{t^{2}}{2 !}+\cdots+\frac{t^{n}}{n !}\right),
\end{aligned}
$$

Penyelesaian eksak Persamaan (13) diperoleh dengan mengambil $n \rightarrow \infty$, sehingga diperoleh

$$
u(x, t)=e^{x}\left(1+t+\frac{t^{2}}{2 !}+\cdots+\frac{t^{n}}{n !}+\cdots\right)
$$

atau

$$
u(x, t)=e^{x+t} .
$$

Akurasi penyelesaian dari Persamaan (13) bergantung kepada banyak iterasi yang digunakan. Gambar 1(a) dan 1(b) masing-masing menunjukkan perbandingan antara penyelesaian eksak dengan penyelesaian hampiran untuk $n=2$ dan $n=8$.

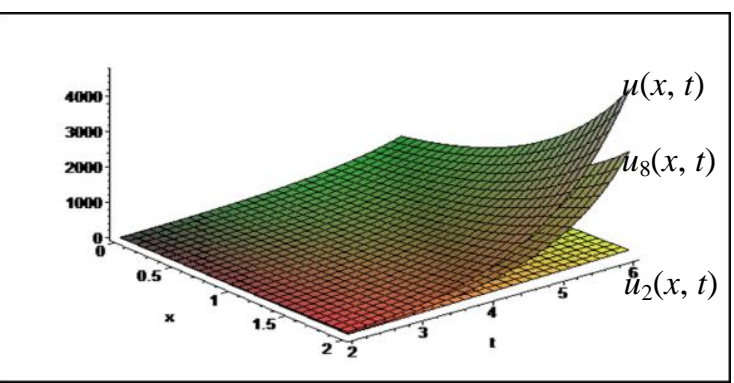

(a)

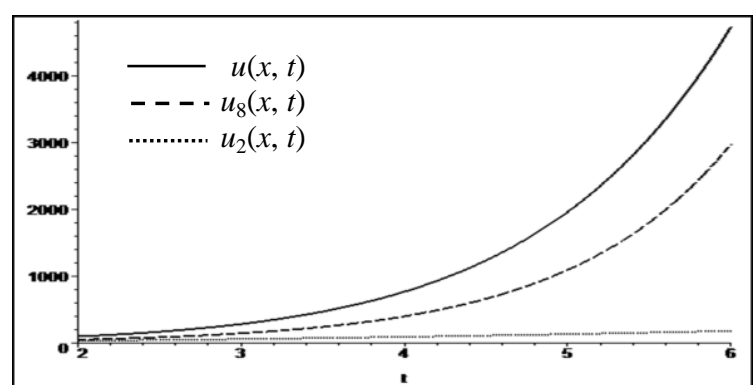

(b)

Gambar 1 Perbandingan solusi eksak dengan $u_{2}(x, t)$ dan $u_{8}(x, t)$ dari Persamaan (13) dengan $2 \leq t \leq 6$ : (a) $0 \leq x \leq 2$, (b) $x=2$. 
Berdasarkan Gambar 1 dapat dilihat bahwa kurva yang dibentuk oleh $u_{8}(x, t)$ lebih mendekati $u(x, t)$ dibandingkan kurva lainnya. Hal ini menunjukkan bahwa penyelesaian hampiran dengan menggunakan iterasi lebih banyak akan mendekati penyelesain eksaknya. Sedangkan untuk memperlihatkan galat yang dihasilkan oleh beberapa penyelesaian hampiran diberikan pada Tabel 1 .

Untuk melihat konvergensi penyelesaian hampiran yang diperoleh, penulis menghitung galat-galat pada iterasi ke- 2, 4, 6, 8, 10 dan 12 menggunakan Persamaan (6) di $x=0,1$ dan $t=0,2 ; 0,4 ; 0,6 ; 0,8$ dan 1,0 . Perbandingan nilai-nilai galat yang telah dihitung diberikan pada Tabel 1 berikut.

Tabel 1 Perbandingan galat beberapa iterasi di $x=0,1$.

\begin{tabular}{|c|c|c|c|c|c|c|}
\hline$t$ & $E_{2}$ & $E_{4}$ & $E_{6}$ & $E_{8}$ & $E_{10}$ & $E_{12}$ \\
\hline 0,2 & $3,8131(\mathrm{e}-3)$ & $7,4974(\mathrm{e}-6)$ & $7,0801(\mathrm{e}-9)$ & $3,9134(\mathrm{e}-12)$ & $1,4183(\mathrm{e}-15)$ & $3,6276(\mathrm{e}-19)$ \\
\hline 0,4 & $3,2143(\mathrm{e}-2)$ & $2,4835(\mathrm{e}-4)$ & $9,2988(\mathrm{e}-7)$ & $2,0452(\mathrm{e}-10)$ & $2,9544(\mathrm{e}-12)$ & $3,0155(\mathrm{e}-14)$ \\
\hline 0,6 & $1,1449(\mathrm{e}-1)$ & $1,9539(\mathrm{e}-3)$ & $1,6311(\mathrm{e}-5)$ & $8,0280(\mathrm{e}-8)$ & $2,6001(\mathrm{e}-10)$ & $5,9558(\mathrm{e}-13)$ \\
\hline 0,8 & $2,6889(\mathrm{e}-1)$ & $8,5379(\mathrm{e}-3)$ & $1,2551(\mathrm{e}-4)$ & $1,0921(\mathrm{e}-6)$ & $6,2651(\mathrm{e}-9)$ & $2,5446(\mathrm{e}-11)$ \\
\hline 1,0 & $5,9335(\mathrm{e}-1)$ & $2,7042(\mathrm{e}-2)$ & $6,1507(\mathrm{e}-4)$ & $8,3142(\mathrm{e}-6)$ & $7,4234(\mathrm{e}-8)$ & $4,6993(\mathrm{e}-10)$ \\
\hline
\end{tabular}

Untuk menggambarkan perubahan kelajuan galat dari Persamaan (13), nilai-nilai galat dari Tabel 1 untuk $t=0,2$ dan $t=1,0$ diplot secara logaritmik sebagaimana yang diberikan pada Gambar 2 berikut.

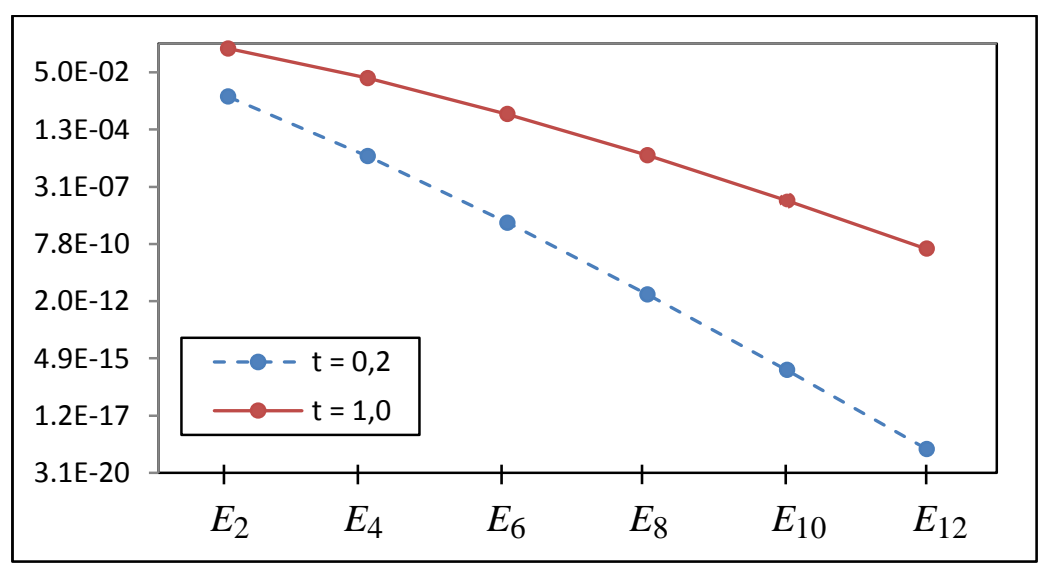

Gambar 2 Perbandingan galat untuk $t=0,2$ dan $t=1,0$.

Berdasarkan Gambar 2 dapat diamati bahwa galat yang dihasilkan akan semakin mengecil ketika iterasi yang yang digunakan semakin banyak. Hal ini menunjukkan bahwa, semakin banyak iterasi yang digunakan, maka penyelesaian hampiran akan semakin mendekati penyelesaian eksaknya. Selain itu, Gambar 2 juga memperlihatkan bahwa secara umum nilai galat menurun secara logaritmik baik untuk $t=0,2$ maupun $t=1,0$.

\section{Contoh 2.}

Pertimbangkan persamaan differensial parsial parabolik nonlinier berikut ini,

$$
\frac{\partial u}{\partial t}+\frac{1}{2} \frac{\partial u^{2}}{\partial x}-u(1-u)=0
$$

dengan nilai awal $u(x, 0)=e^{-x}[10]$ 


\section{Wartono, Mohammad Hanafi, Irma Suryani}

Penyelesaian persamaan parabolik nonlinier pada persamaan (15) dilakukan dengan menentukan nilai $u_{1}(x, t), u_{2}(x, t), u_{3}(x, t), \ldots, u_{n}(x, t)$. Selanjutnya dengan menggunakan Persamaan (12), maka Persamaan (15) menjadi

$$
u_{n+1}(x, t)=u_{n}(x, t)-\int_{0}^{t}\left(\frac{\partial u_{n}(x, \tau)}{\partial \tau}+\frac{1}{2}\left(\frac{\partial u_{n}^{2}(x, \tau)}{\partial x}\right)-u_{n}(x, \tau)\left(1-u_{n}(x, \tau)\right)\right) d \tau
$$

Berdasarkan Persamaan (16) dan syarat awal $u(x, 0)=e^{-x}$, diperoleh

$$
\begin{aligned}
& u_{1}(x, t)=e^{-x}(1+t), \\
& u_{2}(x, t)=e^{-x}\left(1+t+\frac{t^{2}}{2 !}\right), \\
& u_{3}(x, t)=e^{-x}\left(1+t+\frac{t^{2}}{2 !}+\frac{t^{3}}{3 !}\right), \\
& u_{n}(x, t)=e^{-x}\left(1+t+\frac{t^{2}}{2 !}+\frac{t^{3}}{3 !}+\cdots+\frac{t^{n}}{n !}\right),
\end{aligned}
$$

Penyelesaian dari persamaan diferensial parabolik (15) dengan mengambil deret tak hingga dalam bentuk

$$
u(x, t)=e^{-x}\left(1+t+\frac{t^{2}}{2 !}+\frac{t^{3}}{3 !}+\cdots+\frac{t^{n}}{n !}+\cdots\right)
$$

atau

$$
u(x, t)=e^{-x+t} .
$$

Akurasi penyelesaian dari persamaan (15) bergantung kepada banyaknya iterasi yang digunakan. Gambar 3 menunjukkan perbandingan penyelesaian hampiran untuk $n=2$ dan 8 .

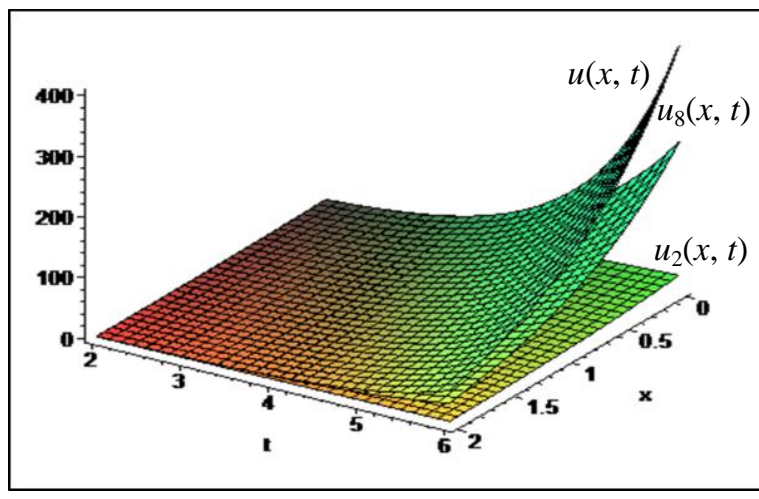

(a)

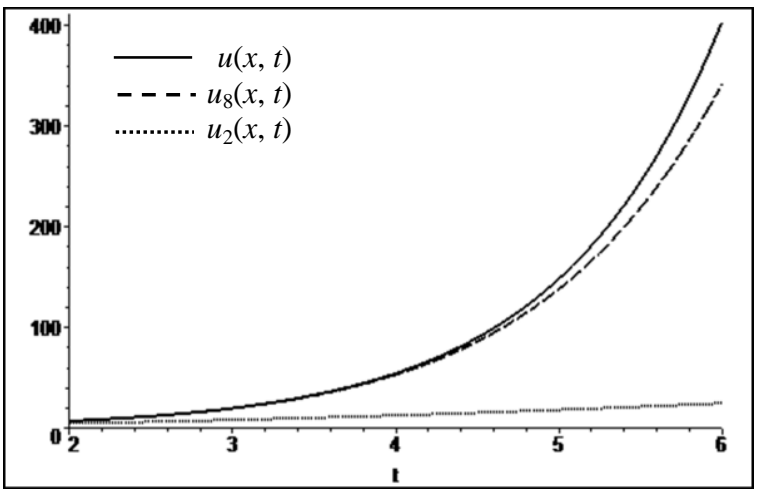

(b)

Gambar 3 Perbandingan solusi eksak dengan $u_{2}(x, t)$ dan $u_{8}(x, t)$ dari Persamaan (15) dengan $2 \leq t \leq 6$ : (a) $0 \leq x \leq 2$, (b) $x=0$.

Berdasarkan Gambar 3 dapat dilihat bahwa kurva yang dibentuk oleh $u_{8}(x, t)$ lebih mendekati $u(x, t)$ dibandingkan kurva lainnya. Hal ini menunjukkan bahwa penyelesaian hampiran dengan menggunakan iterasi lebih banyak akan mendekati penyelesain eksaknya. Sedangkan untuk memperlihatkan galat yang dihasilkan oleh beberapa penyelesaian hampiran diberikan pada Tabel 2.

Untuk melihat konvergensi penyelesaian hampiran yang diperoleh, penulis membandingkan galat-galat pada iterasi ke- 2, 4, 6, 8, 10 dan 12 dengan menggunakan 
Persamaan (6) untuk $x=0,1$ dan $t=0,2 ; 0,4 ; 0,6 ; 0,8$ dan 1,0 . Nilai-nilai perbandingan galat yang telah dihitung diberikan pada Tabel 2 berikut.

Tabel 2 Perbandingan galat dari beberapa iterasi di $x=1$, dan $t=0,2 ; 0,4 ; 0,6 ; 0,8 ; 1,0$.

\begin{tabular}{|c|c|c|c|c|c|c|}
\hline $\mathrm{t}$ & $E_{2}$ & $E_{4}$ & $E_{6}$ & $E_{8}$ & $E_{10}$ & $E_{12}$ \\
\hline 0,2 & $5,1604(\mathrm{e}-4)$ & $1,0147(\mathrm{e}-6)$ & $9,5818(\mathrm{e}-10)$ & $5,2963(\mathrm{e}-13)$ & $1,9194(\mathrm{e}-16)$ & $4,9094(\mathrm{e}-20)$ \\
\hline 0,4 & $4,3501(\mathrm{e}-3)$ & $3,3611(\mathrm{e}-5)$ & $1,2585(\mathrm{e}-7)$ & $2,7678(\mathrm{e}-10)$ & $3,9985(\mathrm{e}-13)$ & $4,0810(\mathrm{e}-16)$ \\
\hline 0,6 & $1,5494(\mathrm{e}-2)$ & $2,6443(\mathrm{e}-4)$ & $2,2074(\mathrm{e}-6)$ & $1,0864(\mathrm{e}-8)$ & $3,5188(\mathrm{e}-11)$ & $8,0604(\mathrm{e}-14)$ \\
\hline 0,8 & $3,8826(\mathrm{e}-2)$ & $1,1554(\mathrm{e}-3)$ & $1,6986(\mathrm{e}-5)$ & $1,4788(\mathrm{e}-7)$ & $8,4788(\mathrm{e}-10)$ & $3,4438(\mathrm{e}-12)$ \\
\hline 1,0 & $8,0301(\mathrm{e}-2)$ & $3,6598(\mathrm{e}-3)$ & $8,3241(\mathrm{e}-5)$ & $1,1252(\mathrm{e}-6)$ & $1,0047(\mathrm{e}-8)$ & $6,3597(\mathrm{e}-11)$ \\
\hline
\end{tabular}

Plot dari nilai-nilai galat pada Tabel 2 untuk $t=0,2$ dan $t=1,0$ ditampilkan pada Gambar 4 berikut.

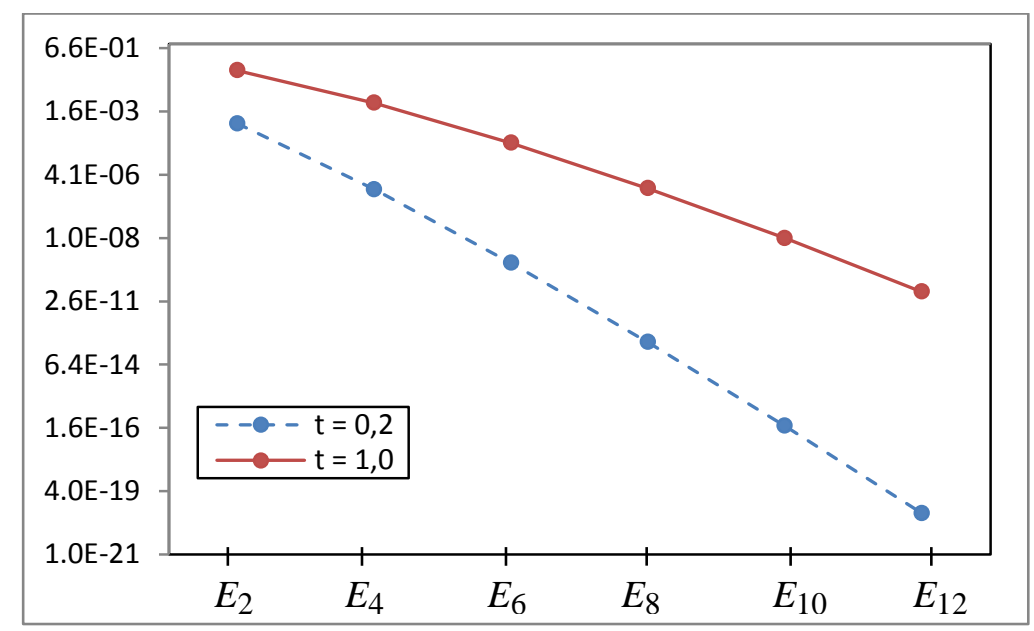

Gambar 4 Perbandingan galat untuk $t=0,2$ dan $t=1,0$.

Gambar 4 memperlihatkan bahwa secara umum galat yang dihasilkan untuk $t=0,2$ lebih kecil dibandingkan $t=1,0$. Selain itu, Gambar 4 juga memperlihatkan bahwa nilai galat dipengaruhi oleh banyaknya iterasi yang digunakan. Nilai galat pada iterasi ke-12 lebih kecil dibandingkan pada iterasi ke-2, 4, 6, 8, dan 10. Penuruan nilai galat pada setiap jumlah iterasi bergerak secara logaritmik. Hal ini menunjukkan bahwa semakin banyak iterasi yang digunakan, maka penyelesaian hampiran dari persamaan (15) akan semakin mendekati penyelesaian eksaknya.

\section{Kesimpulan}

Pada artikel ini, penulis mengkaji penyelesaian persamaan parabolik nonlinear $u_{\mathrm{t}}=u_{x x}+$ $\phi(u)+g(x, t)$ dan syarat awal $u(x, 0)=f(x)$ menggunakan metode iterasi variasi. Untuk menguji metode ini, selanjutnya diberikan dua contoh numerik. Berdasarkan contoh yang diberikan diperoleh bahwa metode iterasi variasi sukses menyelesaikan persamaan diferensial parabolik. Penyelesaian eksaknya diperoleh dengan mengambil iterasi tak hingga. Berdasarkan Gambar 1 dan 3 dapat dilhat bahwa penggunaan iterasi yang semakin banyak menghasilkan penyelesaian hampiran yang semakin mendekati penyelesaian eksaknya. Selain 


\section{Wartono, Mohammad Hanafi, Irma Suryani}

itu, untuk melihat kelajuan galat metode iterasi variasi, galat dihitung pada iterasi ke 2, 4, 6, 8,10 dan 12. Hasil komputasi menunjukkan bahwa semakin banyak iterasi yang digunakan, galat semakin mengecil secara logaritmik sebagaimana yang ditunjukkan pada Tabel 1 dan 2 .

\section{Daftar Pustaka}

[1] Polyanin, A. D., \& Zaitsev, V. F.2012.. Handbook of Nonlinear Partial Differential Equations, CRC Press, Boca Raton.

[2] Adomian, G. 1988. A Review of the Decomposition Method in Applied Mathematics. Journal of Mathematical Analysis and Applications, Vol. 135, hal. 501 544.

[3] Soufyane A,. \& Boulamlf, M. 2005. Solution of Linear and Nonlinear Parabolic Equations by the Decomposition Method. Applied Mathematics and Computation, Vol. 162, hal. 687-693.

[4] Biazar, J., \& Ayati, Z. 2006. An Approximation to the Solution of Parabolic Equation by Adomian Decomposition Method and Comparing the Result with Crank-Nicolson Method. International Mathematical Forum, Vol. 1, No. 39, hal. 1925 - 1933.

[5] Wartono \& Muda, Y. 2011. Aproksimasi Metode Dekomposisi Adomian pada Persamaan Hiperbolik Nonlinier. Jurnal Sains, Teknologi dan Industri, Vol. 9, No. 1, hal. $97-103$.

[6] Wartono \& Muhaijir, M. N. 2013. Penyelesaian Persamaan Riccati dengan Menggunakan Metode Dekomposisi Adomian Laplace. Jurnal Sains, Teknologi dan Industri, Vol. 10, No. 2, hal. 97 - 101.

[7] Liao, S. 1998. Homotopy Analysis Method: A New Analytic Method for Nonlinear Problems. Applied Mathematics and Mechanics, Vol. 19, No. 10, hal. 957 - 962.

[8] Liao, S. 2004. On the Homotopy Analysis Method for Nonlinear Problems. Applied Mathematics and Computation, Vol. 147, hal. 499 - 513.

[9] Jafari, H., Chun, C., Seifi, S., \& Saeidy, M. 2009. Analytical Solution for Nonlinear Gas Dynamic Equation by Homotopy Analysis Method. Applications and Applied Mathematics, Vol. 4, No. 1, hal. 149 - 154.

[10] Chen, C. L., \& Liu, Y. C. 1998. Solution of Two-Point Boundary-Velue Problems Using the Differential Transformation Method. Journal of Optimization Theory and Applications, Vol. 99, No. 1, hal. 23 - 35.

[11] Mirzaee, F. 2011. Differential Tranform Method for Solving Linear and Nonlinear of Ordinary Differential Equations. Applied Mathematical Sciences, Vol. 5, No. 70, hal. $3465-3472$.

[12] He, J. 1999. Homotopy Pertubation Technique. Computer Methods in Applied Mechanics ans Engineering, Vol. 178, hal. 257 - 262.

[13] Mantifar, M., \& Ghanbari, M. 2009. Homotopy Pertubation Method fot the Fisher's Equation and Its Generalized. International Journal of Nonlinear Science, Vol. 8, No. 4 , hal. $448-455$.

[14] He, J. 1997. A New Approach to Nonlinear Partial Differential Equations. Communications in Nonlinear Science and Numerical Simulation, Vol. 2, No. 4, hal. $230-235$. 


\section{Wartono, Mohammad Hanafi, Irma Suryani}

[15] _ . 1999. Variational Iteration Method - A Kind of Non-Linear Analytical Technique : Some Examples. International Journal of Non-Linear Mechanics, Vol. 34, hal. $699-708$.

[16] Batiha, B., Noorani, M. S. M., \& Hashim, I. 2008. The Solution of the One Species Lotka-Volterra Equation Using Variational Iteration Method. Malaysian Journal of Mathematical Sciences, Vol 2, No. 2, hal. 55 - 60.

[17] Ghotbi, A. R., Barari, A., Omidvar, M., \& Ganji, D. D. 2009. Aplication of Variational Iteration Method to Parabolic Problem. Applied Mathematical Sciences, Vol. 3, No. 19, hal. 927-934.

[18] Biazar, J. 2010. Variational Iteration Method for Linear and Nonlinear System of Integro-Differential Equations. Interantional Mathematical Forum, Vol. 5, No. 64, hal. $3185-3191$.

[19] Wazwaz, A. M., \& Khuri, S. A. 2015. The Variational Iteration Method for Solving the Volterra Integro-Differential Forms of the Lane-Emnden and the Emnden-Fowler Problems with Intial and Boundary Value Conditions. Open Engineering, Vol. 5, hal. $31-41$.

[20] Narayanamoorthy, S., \& Mathankumar, S. 2018. Variational Iterative Method: An Approriate Numerical Scheme for Solving System of Linear Volterra Fuzzy IntegroDifferential Equations. Advances in Difference Equations, Vol. 394, hal. 1 - 15.

[21] Tatari, M., \& Dehghan, M. 2007. On the Convergence of He's Variational Iteration Method. Journal of Computational and Applied Mathematics, Vol 207, hal. 121 - 128. 